\title{
Edukasi pelestarian sumberdaya dan lingkungan pantai pada nelayan perikanan bagan
}

\author{
Sulistiono Sulistiono, Zulkarnaen Zulkarnaen, Thomas Nugroho \\ Institut Pertanian Bogor. Jalan Raya Dramaga, Kampus IPB Dramaga Bogor, 1668o, Indonesia \\ * Corresponding Author. Email: onosulistiono@gmail.com \\ Received: 8 November 2018; Revised: 10 December 2018; Accepted: 21 December 2018
}

\begin{abstract}
Abstrak
Perikanan bagan merupakan salah satu pekerjaan yang umum dilakukan masyarakat Desa Saramaake, Halmahera Timur. Kegiatan edukasi pelestarian sumberdaya dan lingkungan pantai ini dilaksanakan pada Juni, Agustus, September dan Desember 2018, bertujuan untuk memberikan edukasi pemahaman tentang pelestarian sumberdaya dan lingkungan pantai di desa tersebut. Metode yang digunakan adalah penyuluhan, diskusi dan monitoring dan evaluasi. Sasaran kegiatan merupakan nelayan dan istri nelayan yang merupakan anggota Kelompok Usaha Bersama (KUB) atau Koperasi. Beberapa kegiatan yang telah dilakukan antara lain penyuluhan tentang perikanan bagan (Agustus), penyuluhan tentang konservasi lingkungan dan sumberdaya (Juni), dan kegiatan monitoring dan evaluasi (September, Desember 2018). Dari hasil kegiatan dapat diketahui bahwa secara umum masyarakat nelayan telah mengetahui dan mengimplementasikan kegiatan perikanan yang baik, dan menjaga kondisi lingkungannya dengan lebih baik, dengan tidak membuang sampah di laut, tidak melakukan penebangan hutan pantai, tidak mengubur ikan by catch di pantai, dan mengingatkan pada sesama nelayan, keluarga dan aparat pemerintah untuk tetap menjaga lingkungan laut.

Kata-kata Kunci: Edukasi, pelestarian, lingkungan, Desa Saramaake, Halmahera Timur.
\end{abstract}

\section{Education on the environmental and resource conservations of the lift-net fishermen}

\begin{abstract}
Lift-net fisheries is a commonly job of the coastal community at Saramaake Village, East Halmahera. This education activity on environmental and resource conservations was done on June, August, September and December 2018, aimed to educate resource and environment conservation in the village. Methods used in this activity were survey in the fied, discussion and filling in the questionnaire form. Objects of the activity were fisherman and their wives who were member of the Common Business Group (KUB-Indonesian) and Cooperative (KoperasiIndonesian). A number of activities were carried out to educate the fisherman community such as extension on the lift net fisheries, extension on the resource and environmental conservation, and monitoring and evaluation. The community commonly knew and implemented a good fishing activity and environmental and resource care better such as no drop garbage to the sea, no using the sea for toilet, no cutting mangrove tree, no burying by catch in coastal area, encouraging to families, fishermen and village officials to keep the sea better.

Keywords: Education, conservation, environment, Saramaake Village, East Halmahera.

How to Cite: Sulistiono, S., Zulkarnaen, Z., \& Nugroho, T. (2018). Edukasi pelestarian sumberdaya dan lingkungan pantai pada nelayan perikanan bagan. JPPM (Jurnal Pendidikan dan Pemberdayaan Masyarakat), 5(2), 179-19o. doi:https://doi.org/10.21831/jppm.v5i2.20716

doi https://doi.org/10.21831/jppm.v5i2.20716
\end{abstract}




\section{JPPM (Jurnal Pendidikan dan Pemberdayaan Masyarakat), 5 (2), 2018 - 180}

Sulistiono Sulistiono, Zulkarnaen Zulkarnaen, Thomas Nugroho

\section{PENDAHULUAN}

Indonesia merupakan negara kepulauan yang terbesar di dunia, dengan garis pantai sepanjang $95181 \mathrm{~km}$ dan luas laut sekitar 5.8 juta $\mathrm{km}^{2}$ atau $70 \%$ dari luas seluruh wilayahnya. Berbagai sumberdaya yang terdapat di dalamnya menjadi objek penting untuk dapat dikaji dalam kerangka pembangunan nasional bangsa Indonesia (Suryati, 2018). Salah satu provinsi di Indonesia, yang memiliki sumberdaya perikanan dan kelautan yang potensial untuk dapat dimanfaatkan dan dikembangkan dalam rangka kesejahteraan masyarakat (baik sebagai sumber protein maupun wisata) adalah Maluku Utara. Di wilayah tersebut terdapat Desa Saramake (Kabupaten Halmahera Timur) yang merupakan salah satu wilayah dengan potensi sumberdaya perikanan (khususnya ikan teri) yang cukup besar. Hasil tangkapan ikan teri tersebut banyak dijual di luar desa tersebut antara lain di pasar Buli dan Ternate (Provinsi Maluku Utara), dan juga telah tersebar sampai di luar Provinsi Maluku Utara (Manado, Surabaya, Makasar, dan lain-lain).

Pemberdayaan merupakan suatu cara dimana rakyat, organisasi dan komunitas diarahkan agar mampu menguasai atau berkuasa atas kehidupannya (Suharto, 2005). Pemberdayaan bertujuan untuk memiliki pengetahuan dan kemampuan dalam memenuhi kebutuhan hidupnya baik yang bersifat fisik, ekonomi maupun sosial. Pemberdayaan hadir, dicanangkan dan diprogramkan sesuai dengan kondisi atau kebutuhan masyarakat setempat sehingga diharapkan hasil dari pemberdayaan dapat membuat perubahan sosial dan sasaran yang tepat pada sebuah komunitas lemah. Pemberdayaan masyarakat telah lama dilakukan oleh berbagai instansi (baik pemerintah maupun perusahaan swasta) dalam rangka meningkatkan kualitas masyarakat di sekitarnya (Suharto, 2005). Edukasi konservasi lingkungan dan sumberdaya merupakan salah satu program pemberdayaan masyarakat yang dilakukan di Desa Saramaake.

Di wilayah negara Indonesia, kegiatan pemberdayaan masyarakat nelayan telah cukup banyak dilakukan oleh beberapa peneliti baik melalui kerja sama dengan perusahaan, maupun dilakukan bersama pemerintah. Beberapa kegiatan pemberdayaan masyarakat tersebut antara lain pemberdayaan masyarakat nelayan di wilayah Kecamatan Tobelo, Kabupaten Halmahera Utara (Maluku Utara) (Sipahelut, 2010), pemberdayaan masyarakat di Kecamatan Lekok, Kabupaten Pasuruan (Jawa Timur) (Nugroho, 2015), pemberdayaan masyarakat di Kecamatan Rao, Kabupaten Pesaman (Sumatera Barat) (Yanti \& Permata, 2016), pemberdayaan masyarakat nelayan di wilayah pesisir Kabupaten Indramayu (Jawa Barat) (Darmansah, Sulistiono, Nugroho, \& Supriyono, 2016a, 2016b; Ma'arif, Zulkarnain, Nugroho, \& Sulistiono, 2016), dan pemberdayaan masyarakat di Pulau Gebe, Kabupaten Halmahera Tengah (Maluku Utara) (Insani et al., 2017; Sulistiono et al., 2012, 2015).

Di daerah Saramaake, juga telah dilakukan beberapa kegiatan pemberdayaan masyarakat nelayan (kerja sama antara perguruan tinggi dan perusahaan), antara lain inisiasi pengembangan pasar produk laut (Budi et al., 2017), peningkatan kualitas hasil dan diversifikasi produk hasil laut (Budi et al., 2017), pengelolaan kegiatan pemberdayaan masyarakat (Sulistiono et al., 2017), upaya sertifikasi produk olahan (sambal teri) (Budi, Purnomo, Sulistiono, Darmanto, \& Arisyono, 2018), dan pengembangan kelembagaan (Kelompok Usaha Bersama menjadi Koperasi) (Sehabudin, Budi, Herawati, Purnomo, \& Sulistiono, 2017). Sedangkan informasi yang berkaitan dengan edukasi terhadap nelayan bagan tentang pelestarian sumberdaya dan lingkungan di wilayah tersebut secara khusus belum disampaikan. Kegiatan ini bertujuan untuk memberikan edukasi pemahaman terhadap nelayan bagan tentang aspek pelestarian sumberdaya dan lingkungan di Desa Saramaake. Dari hasil kegiatan ini, diharapkan masyarakat dapat menjaga lingkungan dan sumberdaya dengan lebih baik, agar terdapat kegiatan perikanan yang berkelanjutan.

\section{METODE}

Kegiatan edukasi tentang pelestarian sumberdaya dan lingkungan bagi para nelayan bagan di Desa Saramaake, Kecamatan Wasile Selatan, Kabupaten Halmahera Timur, Provinsi Maluku Utara (Gambar 1), 
JPPM (Jurnal Pendidikan dan Pemberdayaan Masyarakat), 5 (2), 2018 - 181

Sulistiono Sulistiono, Zulkarnaen Zulkarnaen, Thomas Nugroho

dilakukan pada Juni, Agustus, September dan Desember 2018, yang merupakan bagian dari kegiatan pemberdayaan masyarakat yang dilakukan selama 6 bulan, sejak Juni sampai Desember 2017 di desa tersebut.

\section{Bahan dan Alat}

Bahan yang diperlukan dalam kegiatan ini adalah bahan penyuluhan (berupa bahan tayangan) yang terdiri dari berbagai form (isian) yang diisi oleh para responden dan ATK. Sedangkan peralatan yang diperlukan berupa peralatan diskusi (LCD, computer, laptop).

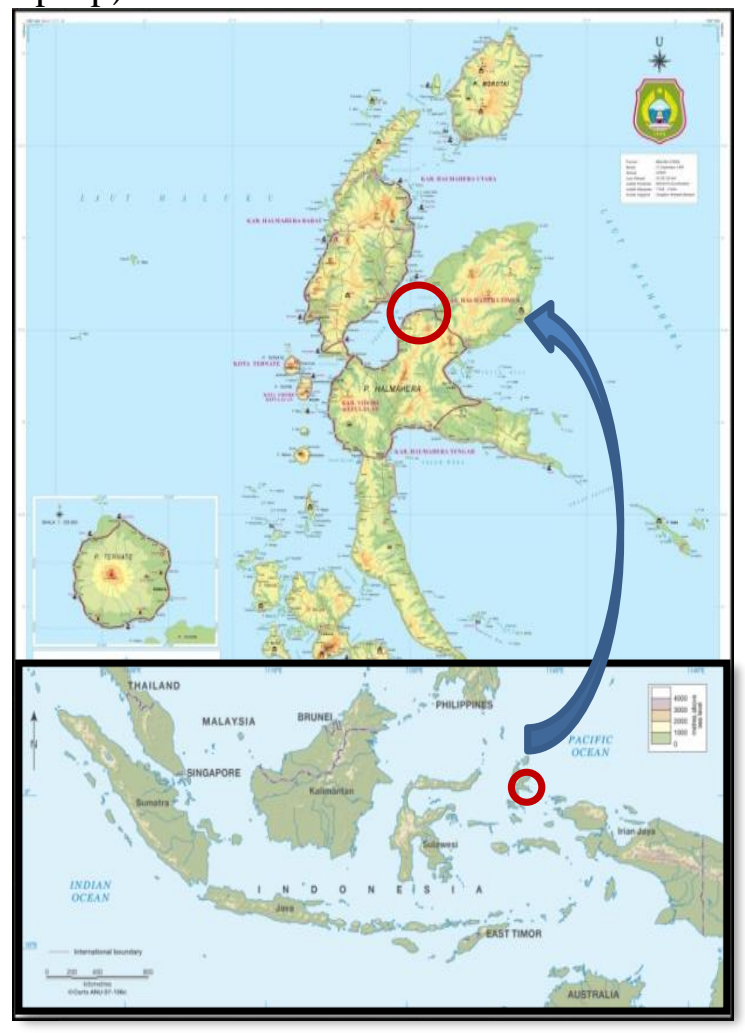

Gambar 1. Lokasi kegiatan edukasi tentang pelestarian sumberdaya dan lingkungan di

Desa Saramaake, Halmahera Timur, Provinsi Maluku Utara

\section{Metode Pelaksanaan dan Data Analisis}

Metode palaksanaan kegiatan dilakukan melalui penyuluhan/pelatihan, peninjauan secara langsung di lapang, diskusi dengan para responden dan pengisian quesionair yang dilakukan oleh responden $(n=28)$. Pada kuesionair diberikan alternative jawaban yang sederhana, melalui dua pilihan yaitu "ya" dan "tidak" pada setiap pertanyaan. Dalam pelaksanaan, kegiatan ini juga dibantu oleh para tenaga pendamping lapang, yang selam kegiatan pemberdayaan masyarakat tinggal di desa tersebut. Data yang didapat dari hasil pengisian kuesionair tersebut, diolah dengan program aplikasi excell dan hasilnya ditampilkan dan dianalisis secara deskriptif.

\section{HASIL DAN PEMBAHASAN}

\section{Hasil}

\section{Perikanan Bagan di Desa Saramaake}

Desa Saramaake merupakan salah satu desa yang terdapat di wilayah bagian selatan Teluk Kao (Kabupaten Halmahera Timur). Di daerah ini sudah cukup lama dikenal sebagai salah satu desa penghasil ikan teri yang cukup besar. Ikan teri yang dihasilkan di wilayah ini tidak hanya dipasarkan di wilayah sekitar, namun sudah sampai ke daerah Ternate dan bahkan sampai ke luar pulau (seperti Surabaya dan Manado). Ikan teri dari wilayah ini tidak hanya dijual secara kering, namun telah dijual dalam bentuk olahan (Budi et al., 2017).

Kegiatan perikanan tangkap ikan teri di Desa Saramaake umumnya dilakukan dengan menggunakan bagan perahu. Bagan perahu merupakan salah satu jenis alat tangkap ikan yang termasuk dalam klasifikasi jaring angkat (dari jenis bagan) yang digunakan nelayan untuk menangkap ikan pelagis kecil. Bagan perahu memiliki bentuk lebih ringan dan sederhana, yang dapat menggunakan satu atau dua perahu. Kontruksi bagan perahu tersebut berupa jaring berbentuk segi empat dan menggunakan dua buah tiang sebagai penggantung dan pembuka jaring, bagian atas jaring diberi alat pelampung dan bagian sebelah bawah diikatkan pemberat. Bagian bawah dilengkapi tali penarik bila dilakukan secara manual, untuk kapal yang telah dilengkapi dengan winch maka di kapal dilengkapi pula relling, yang banyaknya sesuai dengan jumlah tali yang dipergunakan. Tali ini berfungsi sebagai penarik dan juga pengangkat jaring dalam air.

Bahan yang digunakan dalam pembuatan bagan antara lain jaring, tali, gantungan jaring, bahan yang dipakai terutama bahan yang kuat dan tahan lama, tahan terhadap beban dan tahan terhadap gesekan, sifat ba- 
JPPM (Jurnal Pendidikan dan Pemberdayaan Masyarakat), 5 (2), 2018 - 182

Sulistiono Sulistiono, Zulkarnaen Zulkarnaen, Thomas Nugroho

han tersebut umumnya terdapat pada bahanbahan tali jaring terbuat dari serat synthesis seperti saran, campuran nilon, tetoran (polyster), polypropelen, vinylon, dan nylon. Selain itu bahan yang digunakan untuk membuat bagan adalah pemberat (timah, besi), pelampung, cincin dan kayu tiang.

Sedangkan untuk kontruksi kapal untuk bagan sangat sederhana dan tidak terlalu sulit untuk di desain, namun ada persyaratan yang harus dipenuhi seperti kontruksi bagan perahu hanyut dibentuk dari kayu, bamboo, waring serta perahu bermotor yang sekaligus sebagai alat transportasi di laut. Bagan perahu hanyut memiliki beberapa bagian diantaranya bagan yang terbuat dari bamboo berbentuk empat persegi panjang yang menyatu dengan perahu ditempatkan diiatas secara melintang, perahu sebagai bagian utama dalam meletakkan bagan, jaring bagan yang terletak dibawah perahu berukuran persegi sama sisi.

Di Desa Saramake, ukuran bagan bervariasi, ada yang berukuran cukup kecil, sedang dan cukup besar. Biaya pembuatannyapun juga bervariasi, ada yang sekitar 40 juta rupiah dan ada pula yang berharga 100 juta rupiah. Biaya untuk pembuatan bagan dengan ukuran kerangka $17 \times 17 \mathrm{~m}^{2}$ umumnya berkisar 6o juta. Jumlah bagan yang dimiliki nelayan juga berbeda-beda (1-3 bagan per orang) (Budi et al., 2017). Beberapa bagan (ukuran, kapasiatas mesin, dan sarana lampu) di Desa Saramaake disampaikan pada Tabel 1.

Kegiatan pengoperasian bagan perahu diawali dengan persiapan menujufishing ground (daerah penangkapan) yang mencakup persiapan bahan-bahan untuk melaut (solar, air, es, minyak tanah, dan lain-lain). Di desa ini, bahan-bahan untuk keperluan pergi menangkap ikan teri dipersiapkan oleh para pemilik bagan. Umumnya, nelayan ke laut sekitar pk 21.oo. Lama penangkapan per trip adalah 6 jam (oo.oo-o6.oo). Ketika sudah sampai ke wilayah fishing ground, umumnya hari menjelang malam. Lampu di bagan dinyalakan dan jaring biasanya tidak langsung diturunkan sampai tiba waktunya ikan terlihat berkumpul di lokasi bagan. Namun demikian ada pula sebagian nelayan yang langsung menurunkan jaring tersebut setelah lampu dinyalakan. Untuk menarik perhatian ikan dinyalakan lampu yang telah terpasang. Setelah menunggu beberapa jam dan ikan mulai terlihat berkumpul dilokasi penangkapan, maka jaring diturunkan ke perairan, jaring biasanya diturunkan secara perlahanlahan dengan memutar roller. Penurunan jaring beserta tali penggantung dilakukan hingga jaring mencapai kedalaman yang diinginkan.

Tabel 1. Deskripsi beberapa bagan di Desa Saramaake, Halmahera Timur.

\begin{tabular}{|c|c|c|c|c|c|c|}
\hline \multirow{2}{*}{ No. Namanelayan pemilik } & \multicolumn{6}{|c|}{ Ukuran perahu Mesin Ukuran bagan Ukuran jaring Genset (watt) I } \\
\hline & $(\mathrm{LOA}) \mathrm{m}$ & $(\mathrm{HP})$ & $(\mathrm{pxl}) \mathrm{m}^{2}$ & $(p x l x d) \mathrm{m}^{3}$ & & (pcs; watt) \\
\hline 1. Awat Rako & 9 & 40 & $17 \times 17$ & $17 \times 17 \times 17$ & 3500 & $40 ; 42$ \\
\hline 2. Mochtar Labile & 14,5 & 40 & $17 \times 17$ & $17 \times 17 \times 15$ & 5000 & $50 ; 42$ \\
\hline 3. Aswin Wawa & 14 & 40 & $14 \times 14$ & $14 \times 14 \times 15$ & 4000 & $40 ; 42$ \\
\hline 4. Suhud Damesu & 13,5 & - & $17 \times 17$ & $17 \times 17 \times 15$ & 4000 & $30 ; 42$ \\
\hline 5. Ade Daud & 11 & 40 & $18 \times 19$ & $18 \times 19 \times 15$ & 4000 & $53 ; 42$ \\
\hline 6. Walid Mambelo & 13 & 40 & $12 \times 12$ & $12 \times 12 \times 13$ & 4000 & $40 ; 42$ \\
\hline 7. Hasan Alim & 11 & 40 & $15 \times 16$ & $15 \times 16 \times 15$ & 4000 & $30 ; 42$ \\
\hline 8. Mahri Jawal & 14 & 40 & $17 \times 17$ & $17 \times 17 \times 15$ & 5000 & $40 ; 42$ \\
\hline 9. Jalal Jangolo & 9 & 40 & $15 \times 16$ & $15 \times 16 \times 17$ & 3500 & $30 ; 42$ \\
\hline 10. Fadli Abli & 15 & 40 & $20 \times 19$ & $20 \times 19 \times 17$ & 5000 & $90 ; 42-50$ \\
\hline 11. Sukardi Tabengki & 14 & 40 & $18 \times 17$ & $18 \times 17 \times 15$ & 4000 & $50 ; 42$ \\
\hline
\end{tabular}

Keterangan: p: panjang, l: lebar, d: kedalaman 
JPPM (Jurnal Pendidikan dan Pemberdayaan Masyarakat), 5 (2), 2018 - 183

Sulistiono Sulistiono, Zulkarnaen Zulkarnaen, Thomas Nugroho

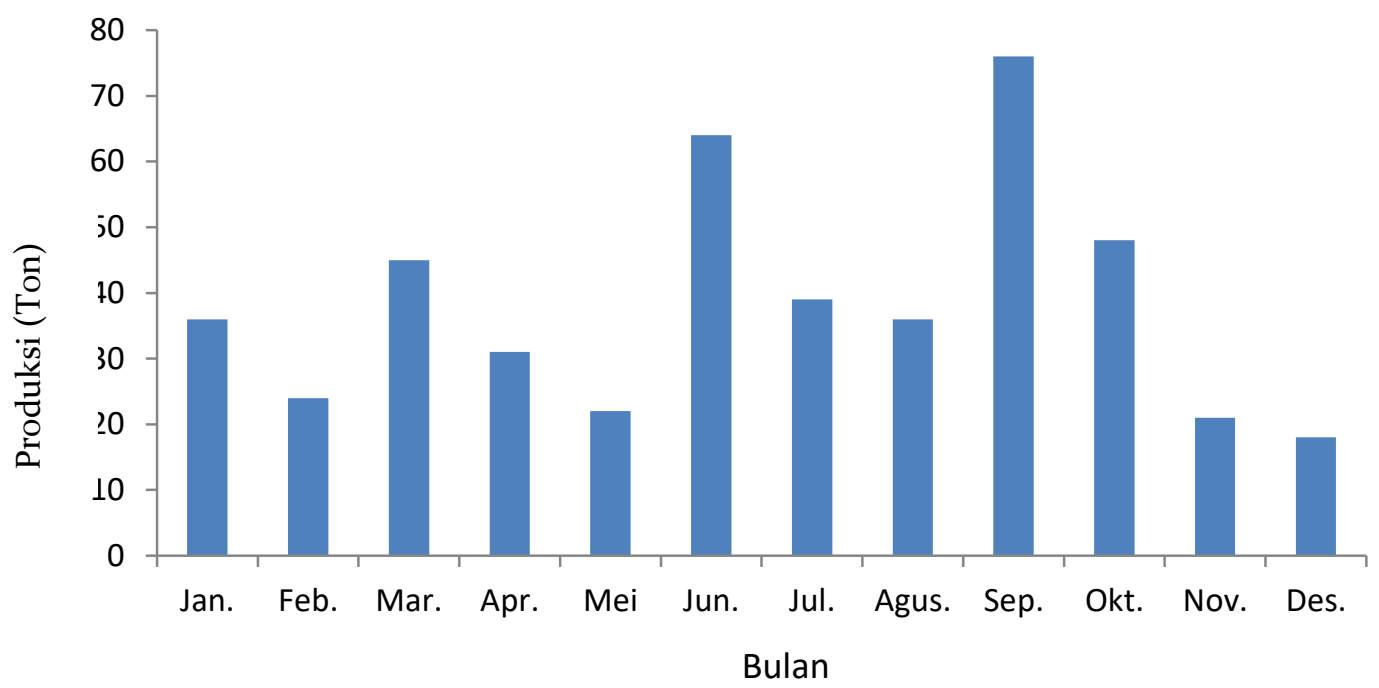

Gambar 3. Produksi ikan teri di Desa Saramaake, selama bulan Januari-Desember 2017

Selama jaring berada dalam air, nelayan melakukan pengamatan tehadap keberadaan ikan di sekitar kapal untuk memperkirakan kapan jaring akan diangkat. Lama jaring berada dalam perairan (perendaman air) bukan bersifat ketetapan. Setelah dikira ikan telah berkumpul di permukaan di atas jaring, dilakukan pengangkatan jaring (lifting). Kegiatan lifting ini diawali dengan pemadaman lampu secara bertahap, hal ini dimaksudkan agar ikan tidak terkejut dan tetap terkonstrasi pada bagian perahu di sekitar lampu yang masih mennyala. Ketika ikan masih terkumpul di tengah-tengah jaring, jaring tersebut mulai diitarik ke permukaan hingga akhirnya ikan akan tertangkap oleh jaring. Lifting dilakukan dengan memulai memadamkan lampu berwarna merah sehingga ikan berkumpul dan lebih naik ke permukaan air, lalu jaring ditarik perlahan dengan tidak menimbulkan suara kejutan dan diangkat ke permukaan dengan mennggunkan tali pengangkat.

Kegiatan penangkapan ikan teri di Desa Saramaake dilakukan hampir setiap hari. Dalam setiap bulan, hari penangkapan secara rata-rata umumnya 14 hari, atau paling lama 21 hari termasuk menangkap cumi (7 hari bulan terang). Biaya operasional kegiatan penangkapan dengan menggunakan bagan berkisar Rp 4-5 juta juta per bulan (hanya untuk BBM), sedangkan untuk akomodasi (makan, minum, rokok) adalah tanggung jawab masing-masing nelayan.
Produk ikan teri kering yang terkumpul di salah satu pengumpul dari Bulan JanuariDesember 2017 disampaikan pada Gambar 3. Grafik tersebut memperlihatkan bahwa produk ikan teri yang dihasilkan sangat bervariasi, cukup tinggi pada Bulan Januari, cenderung menurun pada Bulan Juni dan naik cukup tinggi pada Bulan September dan Oktober. Hasil tangkapan ikan teri tergantung dari beberapa hal, antara lain musim hujan ataupun musim barat (kondisi laut).

Edukasi Perikanan Bagan dan Lingkungan serta Sumberdaya Ikan

Wilayah pesisir merupakan daerah peralihan laut dan daratan. Kondisi tersebut menyebabkan wilayah pesisir mendapatkan tekanan dari berbagai aktivitas dan fenomena di darat maupun di laut. Fenomena yang terjadi di daratan antara lain abrasi, banjir dan aktivitas yang dilakukan oleh masyarakat yaitu pembangunan permukiman, penebangan hutan untuk persawahan, pembangunan tambak yang pada akhirnya memberi dampak pada ekosistem pantai. Demikian pula fenomena-fenomena di laut, seperti pasang surut air laut, gelombang badai dan sebagainya (Hastuti, 2012). Faktor alam lainnya yang juga menyebabkan kerusakan lingkungan adalah gempa dan gelombang tsunami dikarenakan rusaknya ekosistem pesisir sehingga tidak ada penghalang sebagai peredam gelombang tsunami (Arifin, 2005).

Secara umum, aktivitas masyarakat pesisir meliputi aktivitas ekonomi berupa 
JPPM (Jurnal Pendidikan dan Pemberdayaan Masyarakat), 5 (2), 2018 - 184

Sulistiono Sulistiono, Zulkarnaen Zulkarnaen, Thomas Nugroho

kegiatan perikanan yang memanfaatkan lahan darat, lahan air, dan laut terbuka; kegiatan pariwisata dan rekreasi yang memanfaatkan lahan darat, lahan air, dan objek di bawah air; kegiatan transportasi laut yang memanfaatkan lahan darat dan alokasi ruang di laut untuk jalur pelayaran, kolam pelabuhan dan lain-lain. Aktivitas ekonomi yang dilakukan bertujuan untuk meningkatkan kesejahteraan masyarakat dengan ketergantungannya terhadap kondisi lingkungan dan sumber daya alam yang ada di sekitarnya, pemerintah dalam pengelolaan lingkungan hidup dan sumberdaya alam, lembaga sosial aktivitas, ekonomi pendidikan, kesehatan dan lain-lain (Bengen, 2001). Namun demikian, setiap aktivitas dan perilaku manusia berpengaruh terhadap lingkungan.

Berkaitan dengan kegiatan pemberdayaan masyarakat, nelayan perikanan bagan di Saramaake diberikan pelatihan dan penyuluhan, agar para nelayan dapat menerapkan kegiatan penangkapan ikan teri dengan baik. Setelah kegiatan penyuluhan dan pelatihan, nelayan diberikan tes dalam bentuk pengisian kuesioner. Dari beberapa pertanyaan yang disampaikan, umumnya nelayan menyampaikan kegiatan pelatihan bermanfaat, sesuai dengan yang diinginkan, dan mendapatkan tambahan keterampilan. Para nelayan juga mengikuti saran yang disampaikan dalam kegiatan pelatihan dan diskusi, antara lain tidak melakukan kegiatan merokok di bagan, tidak membuang sampah di bagan, dan melakukan pencucian ikan teri dengan air yang bersih). Hasil pengamatan berdasarkan pengisian kuesioner disampaikan pada Gambar 4. Dalam rangka kegiatan perikanan bagan yang berkesinambungan, nelayan diberikan penyuluhan tentang edukasi konservasi lingkungan perairan dan pelestarian sumberdaya ikan. Kegiatan ini dimaksudkan agar masyarakat mampu menjaga lingkungan pantai dengan lebih baik, dengan cara tidak melakukan pengotoran pantai, dengan membuang sampah ataupun MCK. Lebih lanjut, masyarakat agar tidak melakukan kegiatan penebangan hutan di sekitar pantai, yang akan mempengaruhi kekeruhan pantai, dan berdampak pada berkurang atau hilangnya sumberdaya ikan teri di laut. Dengan memperhatikan dan melakukan kegiatan yang tidak mencemari laut, diharapkan ikan teri tetap dapat ditangkap di perairan pantai Saramaake. Kegiatan edukasi ini dilakukan selama 2 hari, yaitu pada 9 dan 10 Juni 2017 di ruang produksi KUB Desa Saramaake, yang dihadiri sekitar 8 orang (hari pertama) dan sekitar 20 orang (hari ke dua) (Gambar 6).

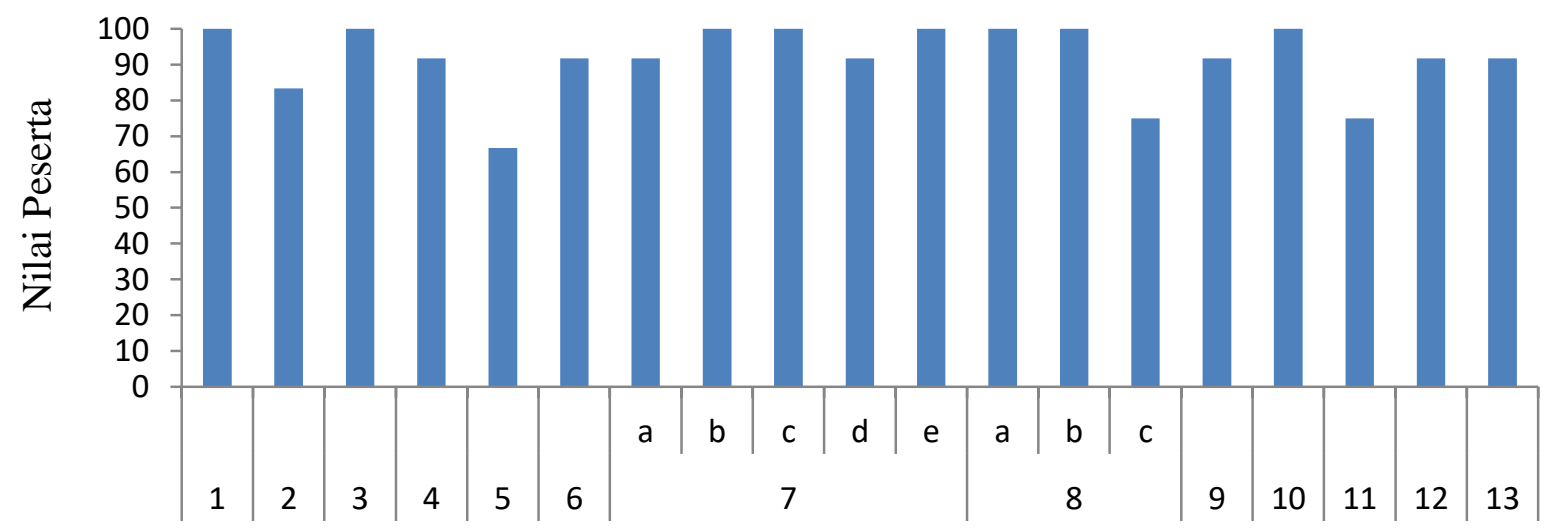

Jenis Pertanyaan

Gambar 4. Hasil monitoring dan evaluasi kegiatan pelatihan perikanan bagan di Desa Saramaake, Halmahera Timur.

Keterangan:

1. Apakah ada manfaat yang diperoleh dari kegiatan ini?

2. Apakah program sudah sesuai dengan yang diharapkan?

3. Apakah kelompok mendapatkan peningkatan ketrampilan?

4. Apakah tempat penjemuran sudah dimanfaatkan dengan maksimal?

5. Apakah tempat jemuran yang diberikan dapat menampung teri yang diperoleh? 
JPPM (Jurnal Pendidikan dan Pemberdayaan Masyarakat), 5 (2), 2018 - 185

Sulistiono Sulistiono, Zulkarnaen Zulkarnaen, Thomas Nugroho

6. Apak tempat penjemuran yang diberikan sudah dirawat dengan baik?

7. Apakah SOP dan tata tertib yang diberikan oleh pendamping sudah dilaksanakan?

a. Tidak merokok saat sedang bekerja di bagan

b. Tidak membuang sampah disekitar bagan

c. Pengambilan air untuk mencuci teri pada lokasi yang jernih dan bersih

d. Tidak menyimpan bahan bakar di gudang

e. Tidak menggunakan kaki pada waktu memasukkan teri kering dalam karung

8. Apakah anggota kelompok bermusyarah bersama dalam memecahkan masalah?

a. Teri yang masih basah

b. Pemasaran teri yang lebih baik

c. Pembuatan bagan baru

9. 9. Apakah menurut anda hasil tangkapan teri masih tinggi?

10. Apabila produksi teri melimpah dan kondisi cuaca tidak mendukung, apakah perlu direbus?

11. Apakah pelatihan instalasi listrik unt lampu di bagan sudah diterapkan?

12.Apakah penerapan pelatihan instalasi listrik di bagan sudah mampu menurunkan angka kematian lampu.

13.Apakah koperasi yang dibentuk sudah memberikan manfaat untuk anggota?

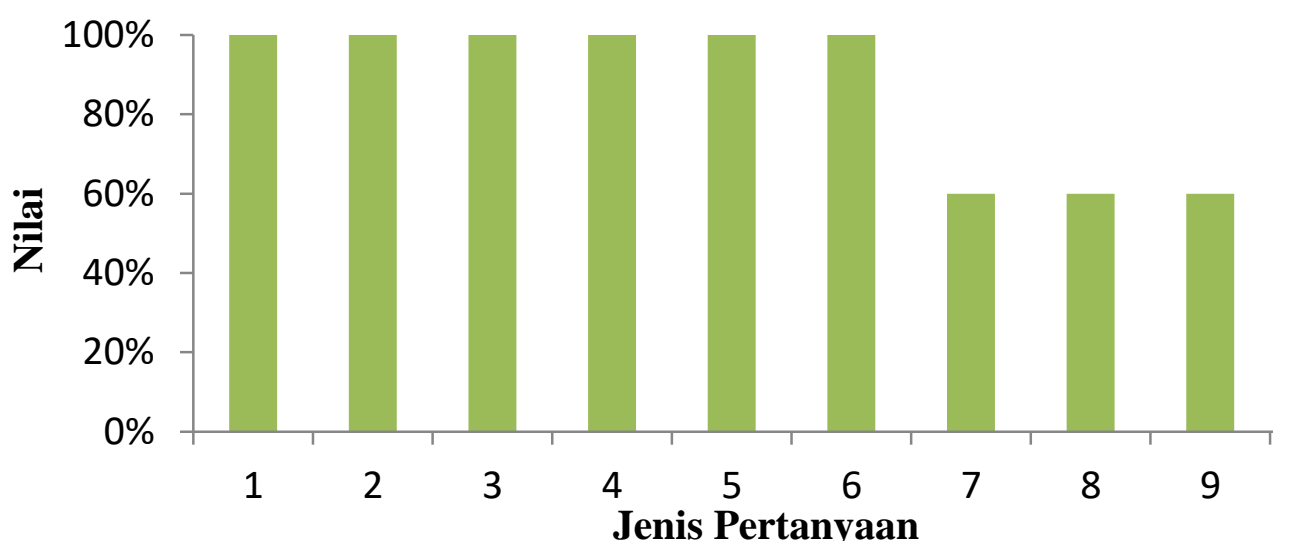

Gambar 5. Hasil monitoring dan evaluasi kegiatan pelatihan edukasi konservasi sumberdaya dan lingkungan, di Desa Saramaake, Halmahera Timur.

Keterangan:

1. Apakah pelatihan pengetahuan konservasi dan pelestarian sdi dapat dipahami dan sudah melaksanaakn dalam kehidupan sehari-hari?

2. Dalam kegiatan apa, telah melaksanakan pelestarian lingkungan? Mmisalnya tidak membuang sampah di laut

3. Dalam kegiatan apa, telah melaksanakan pelestarian lingkungan? Misalnya tidak buang air besar (BAB) di laut

4. Dalam kegiatan apa, telah melaksanakan pelestarian lingkungan? misalnya tidak melakukan penebangan pohon mangrove

5. Dalam kegiatan apa, telah melaksanakan pelestarian lingkungan? misalnya tidak megubur ikan di pantai

6. Dalam kegiatan apa, telah melaksanakan pemanfaatan sumberdaya dan tidak mensia-siakan hasil tangkapan? misalnya memnafaatkan ikan yang ditangkap tapi harganya murah sebagai produks olahan

7. Apakah pernah saling mengingatkan pada keluarga untuk tidak membuang sampah di laut?

8. Apakah pernah saling mengingatkan pada sesame nelayan untuk tidak membuang sampah di laut?

9. Apakah pernah saling mengingatkan pada pemerintah desa untuk tidak membuang sampah di laut?

Sedangkan hasil pengamatan kegiatan monitoring dan evaluasi berkaitan dengan lingkungan disampaikan pada Gambar 5. Dari hasil pengamatan tersebut dapat diketahui bahwa nelayan dapat memahami makna konservasi sumberdaya dan lingkungan pantai, melaksanakan anjuran agar tidak membuang sampah di laut, tidak menjadikan laut sebagai toilet, tidak melakukan penebangan mangrove, tidak membuang by catch di laut, namun memanfaatkan by catch tersebut sebagai ikan olahan yang dapat dijual, 
JPPM (Jurnal Pendidikan dan Pemberdayaan Masyarakat), 5 (2), 2018 - 186

Sulistiono Sulistiono, Zulkarnaen Zulkarnaen, Thomas Nugroho

dan mengingatkan keluarga, teman dan aparat desa agar tetap menjaga laut dengan lebih baik.

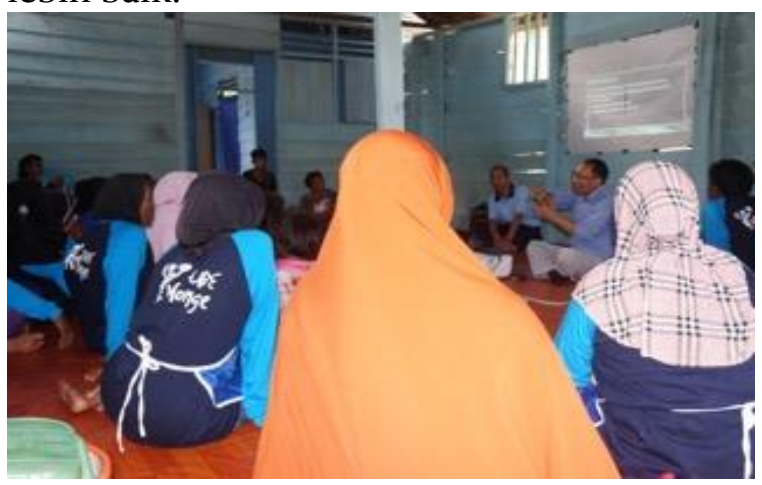

Gambar 6. Edukasi lingkungan perairan dan pelestarian sumberdaya ikan pada masyarakat Desa Saramaake, Halmahera

Timur

\section{Pembahasan}

Pada prinsipnya, manusia memiliki perilaku yang berbeda-beda tergantung dari bagaimana manusia atau individu berinteraksi dengan lingkungannya. Dalam kaitannya dengan lingungan hidup, perilaku manusia dapat menentukan keberlanjutan kondisi lingkungan. Perilaku pengelolaan lingkungan hidup bertujuan untuk memenuhi kebutuhan hidup (saat ini) tanpa merusak atau menurunkan kemampuan generasi mendatang untuk memenuhi kebutuhan hidupnya. Kerangka pendekatan yang digunakan dalam pengelolaan lingkungan hidup adalah pendekatan keterpaduan dalam mengoptimalkan pemanfaatan sumber daya pesisir dan lautan. Azhari (1997) menyatakan bahwa pengelolaan lingkungan hidup adalah suatu upaya terpadu untuk melestarikan fungsi lingkungan hidup, yang meliputi: penataan, pemanfaatan, pemulihan, pengawasan, dan pengendalian yang terus menerus dilakukan untuk pelestarian keseimbangan ekologi lingkungan. Keseimbangan ekologi akan menjamin tercapainya keberhasilan pembangunan yang berkelanjutan.

Berbagai masalah lingkungan berkaitan dengan pengetahuan, sikap, perilaku dan penilaian manusia terhadap lingkungan. Hasil penelitian (Harris, 2006) tentang kondisi lingkungan di Cina menunjukkan bahwa tingkat pendidikan dan pengetahuan, gaya hidup, dan persepsi orang terhadap seberapa berharganya lingkungan, menentukan perilaku manusia terhadap lingkungan. Lebih lanjut, kurangnya kesadaran dan pemahaman masyarakat tentang kebijakan wilayah pesisir, tingkat pendidikan masyarakat yang rendah, watak masyarakat, serta tekanan biaya hidup menyebabkan masyarakat pesisir sering melakukan perusakan lingkungan pesisir (Primyastanto, Dewi, \& Susilo, 2010). Hal ini diperkuat bahwa kerusakan pesisir lebih dipengaruhi oleh faktor alam dan manusia (Gumilar, 2012; Vatria, 2010). Hiariey \& Romeon (2013) menambahkan bahwa tingkat pendidikan, persepsi, dan pendapatan mempengaruhi kepentingan terhadap pemanfaatan wilayah pesisir. Pengaruh pendapat masyarakat terhadap lingkungan merupakan bagian dari mekanisme yang menghasilkan perilaku yang nyata dari masyarakat itu sendiri dalam menciptakan perubahan lingkungan (Ahimsa-Putra, 1994).

Dilihat dari kegiatannya, perikanan bagan di Desa Saramaake masih bersifat konvensional, namun demikian dilihat dari jumlah bagan yang beroperasi, nampak semakin banyak. Pada tahun 2016, di desa ini terdapat sekitar 15 bagan (Budi et al., 2017; Sehabudin et al., 2017), namun pada tahun 2017 terdapat sekitar 30 bagan. Kondisi demikian menunjukkan perkembangan jumlah alat tangkap bagan yang semakin banyak. Dalam kurun waktu 1 tahun terdapat pertambahan sebanyak $100 \%$. Produki yang dihasilkannyapun juga bertambah semakin besar. Pada tahun 2016, produksi berkisar sekitar 10 -39 ton (Gambar 7), sedangkan pada tahun 2017 produksi tersebut semakin besar (pada Oktober 2017, produksi ikan teri di Desa Saramaake sekitar 50 ton) (Gambar 3), sekitar 100\% dari produksi pada bulan yang sama pada tahun 2016. 
JPPM (Jurnal Pendidikan dan Pemberdayaan Masyarakat), 5 (2), 2018 - 187

Sulistiono Sulistiono, Zulkarnaen Zulkarnaen, Thomas Nugroho

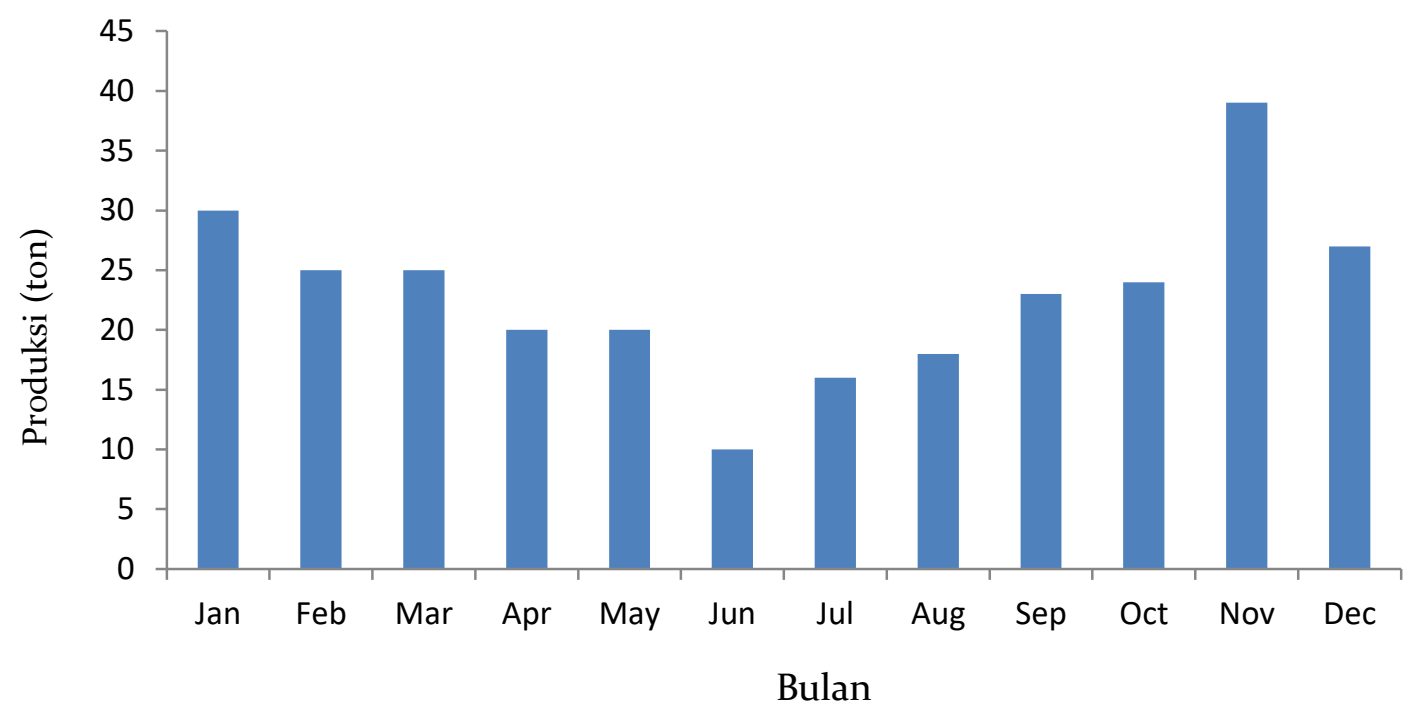

Gambar 7. Produksi Ikan Teri (2016) dari Desa Saramaake, Halmahera Timur (Budi et al., 2017)

Kondisi tersebut juga penting untuk diberikan penyuluhan tentang pentingnya konservasi sumberdaya agar tidak terjadi eksploitasi yang besar, melebihi dari MSY produksi ikan tersebut. Berbagai kegiatan yang dilakukan antara lain: tidak membuang sampah di laut, tidak melakukan pembuangan limbah ke laut, penebangan tumbuhan pantai, menjadikan laut sebagai toilet ataupun mengubur by catch di laut seperti yang selama ini dilakukan oleh masyarakat.

Dari hasil pengamatan ternyata masyarakat telah melakukan apa yang selama ini disampaikan, baik melalui kegiatan pelatihan ataupun melalui pendamping. Peran pendamping juga sangat besar dalam mengubah mainset pemikiran masyarakat nelayan. Dengan seringnya bertemu dan diskusi dengan para pendamping (agen perubahan), masyarakat juga akan semakin bijak dalam mengelola laut ataupun upaya konservasi laut.

Sumber daya pesisir merupakan unsurunsur hayati dan nonhayati yang terdapat di wilayah laut, dimana unsur hayati terdiri atas ikan, mangrove, terumbu karang, padang lamun dan biota lain beserta ekosistemnya. Unsur non-hayati terdiri dari sumberdaya di lahan pesisir, permukaan air, di dalam airnya dan di dasar laut. Sumberdaya hayati yang dimanfaatkan dapat diperbaharui selama laju regenerasi sumberdayanya masih layak untuk berkembang secara alami. Sedang substitusi sumberdaya tersebut untuk menggantikan fungsinya (Idris, 2001).

Pada kegiatan edukasi-pemahaman pelestarian sumberdaya dan lingkungan ini dilakukan dalam rangka penguatan kegiatan ekonomi masyarakat (melalui program pemberdayaan masyarakat). Kegiatan tersebut penting untuk disampaikan, karena cukup banyak masyarakat nelayan yang membuang hasil tangkapan (by catch) selain ikan teri (pada tahun 2016) dan mengubur ikan-ikan tersebut di wilayah pantai. Saat ini ikan-ikan tersebut (by catch) telah mampu diolah menjadi produk yang cukup menguntungkan masyarakat (misalnya menjadi dendeng makechina) (Sulistiono et al., 2017).

Kegiatan pelestarian sumberdaya perikanan bagan saramaake melalui pemberdayaan dan pelatihan dapat dipandang sebagai strategi meningkatkan kapasitas pengetahuan dan mengaktualisasikan potensi masyarakat lokal dalam mengelola dan menjaga sumberdaya perikanan teri (Durand \& Vázquez, 2011). Potensi masyarakat local yang dimaksud meliputi pengalaman dan ketrampilan memahami informasi biologi dan ekosistem sumberdaya perikanan teri termasuk kemampuan mentransformasi pengalaman dan ketrampilan tersebut ke dalam perilaku dan kebiasaannya untuk menjaga kelestarian sumberdaya perikanan teri.

Keberhasilan dalam melestarikan perikanan bagan ini bisa menjadi promosi yang efektif dalam mereplikasi kegiatan serupa 
JPPM (Jurnal Pendidikan dan Pemberdayaan Masyarakat), 5 (2), 2018 - 188

Sulistiono Sulistiono, Zulkarnaen Zulkarnaen, Thomas Nugroho

pada komunitas yang lebih luas. Sebab keberhasilan tersebut mengandung informasi yang berguna dan memberikan contoh yang baik (best practice) dalam mengontrol aktivitas masyarakat dalam memanfaatkan dan mengeksploitasi sumberdaya perikanan dengan beragam spesies di Desa Saramaake dan sekitarnya.

Hal lain yang dapat dikemukakan dari proses pelestarian sumberdaya perikanan bagan adalah adanya partisipasi aktif dari masyarakat lokal. Selain itu dukungan pemerintah dan akademisi bertujuan menjaga motivasi masyarakat agar konsisten dalam menjalankan aktivitas konservasi. Partisipasi masyarakat dalam pelestarian perikanan bagan semakin terjaga dan terpelihara apabila benefit yang diterimanya juga signifikan (Durand \& Vázquez, 2011).

Bertitik tolak dari kegiatan yang dilakukan, diharapkan para nelayan telah memiliki pengetahuan tentang upaya koservasi sumberdaya dan lingkungan. Ikan juga diberi kesempatan untuk kiranya dapat bertelur dan meneruskan keturunannya. Namun dalam kegiatan ini belum ada upaya pelarangan pada waktu-waktu tertentu agar ikan diberi kesempatan bereproduksi. Kedepan, upayaupaya yang lebih dalam tentang pelestarian dan kegiatan aksi juga penting untuk diimplementasikan dalam rangka melestarikan sumberdaya daya dan usaha perikanan teri di Desa Saramaake.

\section{SIMPULAN}

Perikanan bagan merupakan pekerjaan yang umum dilakukan oleh masyarakat pantai Desa Saramaake, Halmahera Timur. Dari hasil kegiatan penyulihuhan-pelatuhan yang telah dilakukan dapat diketahui bahwa secara umum masyarakat nelayan dan istri nelayan telah mengerti dan mengimplementasikan kegiatan perikanan yang baik, dan menjaga kondisi lingkungan cukup baik, dengan tidak membuang sampah di laut, tidak melakukan penebangan hutan pantai, tidak mengubur ikan hasil samping di pantai, dan mengingatkan pada sesama nelayan, keluarga dan aparat pemerintah untuk menjaga lingkungan pantai di desa tersebut.

UCAPAN TERIMA KASIH
Kami mengucapkan terima kasih atas segala bantuan Taufik M. Yusuf, SPi., dan Irma Sabriyani, SKel., MT. (pendamping lapang) dan Mona Lestarilani, M.Si (asisten) yang telah membantu dalam kegiatan ini. Ucapan terimaksih disampaikan kepada PT Antam, Tbk atas fasilitasi pembiayaan dan bantuan lainnya dalam rangka pelaksanaan Program Pemberdayaan Masyarakat Nelayan Desa Saramaake, Kabupaten Halmahera Timur.

\section{DAFTAR PUSTAKA}

Ahimsa-Putra, H. S. (1994). Antropologi ekologi: Beberapa teori dan perkembangannya. Jakarta: Masyarakat Indonesia.

Arifin, S. (2005). Strategi untuk mengurangi kerusakan lingkungan yang diakibatkan oleh gempa dan gelombang tsunami. Jurnal Arsitektur "ATRIUM, 2(1), 28-33.

Azhari, S. (1997). Etika lingkungan dalam pembangunan berkelanjutan. Jakarta: Direktorat Jenderal Pendidikan Tinggi, Departemen Pendidikan dan Kedudayaan.

Bengen, D. G. (2001). Pedoman teknis pengenalan dan pengelolaan ekosistem mangrove. Bogor: Pusat Kajian Sumberdaya Pesisir dan LautanInstitut Pertanian Bogor.

Budi, F. S., Herawati, D., Purnomo, J., Sehabudin, U., Sulistiono, S., \& Nugroho, T. (2017). Peningkatan kualitas dan diversifikasi produk ikan teri untuk pemberdayaan masyarakat di Desa Saramaake, Halmahera Timur. Agrokreatif: Jurnal Ilmiah Pengabdian Kepada Masyarakat, 3(2), 89-99.

Budi, F. S., Purnomo, J., Sulistiono, S., Darmanto, D., \& Arisyono, A. (2018). Pengembangan produk ikan teri dan sertifikasinya dalam rangka pemberdayaan masyarakat di Desa Saramaake, Halmahera Timur, Maluku Utara. Agrokreatif: Jurnal Ilmiah Pengabdian Kepada Masyarakat, 4(2), 143-155.

https://doi.org/10.29244/agrokreatif.4. 2.143-155 
JPPM (Jurnal Pendidikan dan Pemberdayaan Masyarakat), 5 (2), 2018 - 189

Sulistiono Sulistiono, Zulkarnaen Zulkarnaen, Thomas Nugroho

Darmansah, A., Sulistiono, S., Nugroho, T., \& Supriyono, E. (2016a). Pemberdayaan masyarakat melalui pengembangan budi daya ikan lele di Desa Balongan, Indramayu, Jawa Barat. Agrokreatif: Jurnal Ilmiah Pengabdian Kepada Masyarakat, $\quad 2(1), \quad 8$. https://doi.org/10.29244/agrokreatif.2.1 .8-16

Darmansah, A., Sulistiono, S., Nugroho, T., \& Supriyono, E. (2016b). Pemberdayaan masyarakat melalui pengembangan polikultur bandeng dan udang di Desa Karangsong, Indramayu, Jawa Barat. Agrokreatif: Jurnal Ilmiah Pengabdian Kepada Masyarakat, 2(2), 92. https://doi.org/10.29244/agrokreatif.2. 2.92-99

Durand, L., \& Vázquez, L. B. (2011). Biodiversity conservation discourses. A case study on scientists and government authorities in Sierra de Huautla Biosphere Reserve, Mexico. Land Use Policy, 28(1), 76-82. https://doi.org/10.1016/J.LANDUSEPO L.2010.04.009

Gumilar, I. (2012). Partisipasi masyarakat pesisir dalam pengelolaan ekosistem hutan mangrove berkelanjutan di Kabupaten Indramayu. Jurnal Akuatika, 3(2). Retrieved from http://jurnal.unpad.ac.id/akuatika/arti cle/view/1623

Harris, P. G. (2006). Environmental perspectives and behavior in China. Environment and Behavior, 38(1), 5-21. https://doi.org/10.1177/00139165052800 87

Hastuti, H. (2012). Wilayah pesisir dan fenomena-fenomena yang terjadi di pantai. Makasar: Universitas Hassanudin.

Hiariey, L. S., \& Romeon, N. R. (2013). Peran serta masyarakat pemanfaat pesisir dalam pengelolaan wilayah pesisir teluk Ambon Dalam. Jurnal Matematika Sains Dan Teknologi, 14(1), 48-61. Retrieved from http://jurnal.ut.ac.id/index.php/JMST/ article/view/406
Idris, I. (2001). Kebijakan Pengelolaan Pesisir Terpadu di Indonesia. Jakarta: Pusat Riset Teknologi Kelautan. Badan Riset Kelautan Dan Perikanan.

Insani, M. T. S., Kadir, I., Utomo, N. B. P., Afandi, R., Sulistiono, S., Nugroho, T., ... Manan, H. (2017). Pengembangan budidaya ikan kerapu bebek (Chromileptes altivelis) di Pulau Gebe, Halmahera Tengah, Maluku Utara. Agrokreatif: Jurnal Ilmiah Pengabdian Kepada Masyarakat, 3(1), 24. https://doi.org/10.29244/agrokreatif.3.1 $.24-33$

Ma'arif, R., Zulkarnain, Z., Nugroho, T., \& Sulistiono, S. (2016). Pemberdayaan masyarakat nelayan melalui pengembangan perikanan tangkap di Desa Majakerta, Indramayu, Jawa Barat. Agrokreatif: Jurnal Ilmiah Pengabdian Kepada Masyarakat, 2(1), 17.

https://doi.org/10.29244/agrokreatif.2.1 $.17-24$

Nugroho, M. (2015). Pemberdayaan masyarakat nelayan di Kabupaten Pasuruan: Kajian pengembangan model pemberdayaan sumberdaya manusia di wilayah pesisir pantai. TEKNOLOGI PANGAN: Media Informasi Dan Komunikasi Ilmiah Teknologi Pertanian, 6(1). Retrieved from

https://jurnal.yudharta.ac.id/v2/index. php/Teknologi-

Pangan/article/view/464

Primyastanto, M., Dewi, R. P., \& Susilo, E. (2010). Perilaku perusakan lingkungan masyarakat pesisir dalam perspektif Islam (Studi kasus pada nelayan dan pedagang ikan di kawasan pantai tambak, Desa Tambakrejo, Kecamatan Wonotirto, Kabupaten Blitar Jawa Timur). Jurnal Pembangunan Dan Alam Lestari, 1(1). Retrieved from https://jpal.ub.ac.id/index.php/jpal/art icle/view/99

Sehabudin, U., Budi, F. S., Herawati, D., Purnomo, J., \& Sulistiono, S. (2017). Inisiasi pengembangan pemasaran ikan teri (stolephorus spp.) dan 
JPPM (Jurnal Pendidikan dan Pemberdayaan Masyarakat), 5 (2), 2018 - 190

Sulistiono Sulistiono, Zulkarnaen Zulkarnaen, Thomas Nugroho

pembentukan kelembagaan dalam rangka pemberdayaan masyarakat di Desa Saramaake, Halmahera Timur. Agrokreatif: Jurnal Ilmiah Pengabdian Kepada Masyarakat, 3(1), 60. https://doi.org/10.29244/agrokreatif.3.1 $.60-70$

Sipahelut, M. (2010). Analisis pemberdayaan masyarakat nelayan di Kecamatan Tobelo Kabupaten Halmahera Utara. IPB (Bogor Agricultural University). Retrieved from https://repository.ipb.ac.id/handle/123 $456789 / 46703$

Suharto, E. (2005). Membangun masyarakat, memberdayakan rakyat: Kajian strategis pembangunan kesejahteraan sosial dan pekerjaan sosial. Bandung: Refika Aditama.

Sulistiono, S., Priyanto, R., Saharudin, S., Adiwirman, A., Syah, D., Setiono, D. J., \& Zulkarnaen, Z. (2012). Pengembangan perikanan, pertanian, peternakan, pengolahan pangan, kelembagaan dan pemasaran di Pulau Gebe (Vol. 192). Bogor.

Sulistiono, S., Priyanto, R., Sunarminato, T., Sumarti, T., Syah, D., Priyambodo, S., ... Herawati, D. (2015). Program pemberdayaan ekonomi masyarakat Kecamatan Pulau Gebe. Bogor.

Sulistiono, S., S, B. F., Herawati, D., Purnomo, J., Sehabudin, U., \& Nugroho, T. (2017).
Pengelolaan pemberdayaan masyarakat pantai (melalui upaya peningkatan kualitas hasil tangkap dan inisiasi pengembangan pemasaran ikan teri (Stolephorus spp) di Saramaake, Halmahera Timur, Maluku Utara): pemetaan kebutuhan, program dan evaluasi.

Suryati, S. (2018). Pemberdayaan ekonomi masyarakat pesisir (PEMP) melalui fortifikasi garam dan pemasarannya di Keruak Lombok Timur. Jurnal Pengabdian Masyarakat MIPA Dan Pendidikan MIPA, 2(1), 55-70. https://doi.org/10.21831/jpmmp.v2i1.188 68

Vatria, B. (2010). Berbagai kegiatan manusia yang dapat menyebabkan terjadinya degradasi ekosistem pantai serta dampak yang ditimbulkannya. Kumpulan E-Journal Belian, 9(1). Retrieved from http://repository.polnep.ac.id/xmlui/h andle/123456789/151

Yanti, D., \& Permata, D. A. (2016). Pemberdayaan masyarakat tani melalui pengembangan produk olahan ikan di Nagari Tarung-tarung, Kecamatan Rao, Kabupaten Pasaman, Sumatera Barat. Agrokreatif: Jurnal Ilmiah Pengabdian Kepada Masyarakat, 2(2), 73. https://doi.org/10.29244/agrokreatif.2. 2.73-8o. 